\title{
SISTEM PENGAMBILAN KEPUTUSAN PENERIMAAN BEASISWA BERPRESTASI DI SMA NEGERI 1 NATAR LAMPUNG SELATAN
}

\author{
Yuli Syafitri, Roly Yansyah, Musyofa \\ AMIK Dian Cipta Cendikia \\ Jl. Cut Nyak Dien No. 65 Palapa Durian Payung, Bandar Lampung \\ ayulisyafitri@gmail.com, roly.yansyah@gmail.com, afoysum@gmail.com
}

\begin{abstract}
Abstrak - Pemberian bantuan pemerintah maupun swasta dalam dunia pendidikan dikenal dengan sebutan beasiswa. Beasiswa merupakan pemberian bantuan berupa keringanan biaya pendidikan sesuai dengan yang ditentukan yang diberikan kepada mahasiswa maupun pelajar. Namun banyak sekali mengalami kendala diantaranya dalam proes pendistribusian beasiswa yang banyak tidak tepat pada sasaran. Sulitnya proses dalam penyeleleksian yang dikarenakan banyaknya data yang tidak lengkap, kreteia yang kurang jelas dan transparan dalam menentukan penerima beasiswa serta banyaknya proses penyaluran dana yang masih ditemukan kurang tepat. Hal ini dikarenakan belum adanya system yang mudah untuk mengolahnya. Berdasarkan banyaknya kendala dirancang sebuah system Sistem Pendukung Keputusan dengan menggunakan metode Analytical Hierarchy Process (AHP) yang ditemukan oleh Thomas L.Saaty. AHP digunakan untuk membantu melakukan proses perhitungan yang berdasarkan perbandingan krriteria dan nilai yang telah ditntukan untuk mengambil sebuah keputusan dan dibangun sebuah aplikasi web dengan menggunakan php dan mysql untuk membantu proses penentuan keputusan dengan cepat. Hasil dari penelitian ini berupa system pendukung keputusan dalam bentuk aplikasi web yang dapat membantu mengolah data berdasarka kritria dan nilai untuk pengambil keputusan penentuan penerima beasiswa siswa/i.
\end{abstract}

Kata Kunci: Beasiswa, Sistem Pendukung Keputusan, Metode Analytical Hierarchy Process (AHP)

\section{PENDAHULUAN}

Di era revolusi industi 4.0 kemajuan tekhnologi dan informasi sekarang ini berkembang dengan teramat pesat, hal ini bias dilihat dengan ditandainya adanya kondisi yang serba berbasis tekhnologi. Nyaris semua kegiatan sudah menggunakan aplikasi yang berbasis tehnologi disemua sector yang ada di dunia . Era Revolusi berbasis informasi dan komunikasi yang melahirkan model peradaban baru yakni pola atau tatanan kehidupan yang tidak dibatasi oleh jarak, ruang dan waktu. Sistem Pendukung Keputusan atau dikenal dengan singkatan SPK merupakah salah satu contoh dari perkembangan tehknologi yang . setiap detiknya mengalami perubahan.

SPK atau Sistem Pendukung Keputusan yang dalam dalam bahasa Inggris nya yaitu DSS (Decision Support System) merupakan bagian dari sebuah sistem informasi yang berbasis komputer termasuk sistem berbasis pengetahuan (manajemen pengetahuan) yang dipakai guna mendukung pengambilan keputusan dalam suatu organisasi atau perusahaan. Jadi, dalam hal ini DSS atau SPK ini memiliki peranan penting untuk perusahaaan/ pemilik saham baik dari kepala bagian/manajer sampai dengan pimpinan tertinggi (presenden direktur) untuk membantu memberikan informasi untuk mengambil sebuah keputuasn atau sebuah kebijakan tertentu dalam sekala besar agar memiliki sebuah parameter yang jelas dan transparan didalam perusahaan. (Gerald, 2017)
SMA NEGERI 1 NATAR memiliki sebuah program untuk siswa yang berprestasi yaitu berupa beasiswa yang di sampaikan kepada siswa/ siswi. Baik beasiswa dari pemerintah maupu yang berasal dari perusahaan/swasta. Untuk mendapatkan beasiswa tersebut maka harus sesuai dengan aturan yang telah di tetapkan. Beasiswa merupakan suatu pemberian bantuan dalam bentuk keringanan dalam hal keuangan yang diberikan kepada per-orangan, mahasiswa ataupun pelajar dalam melaksanakan pendidikan. Namun, masih banyak kendala dalam proses pendistribusian beasiswa yang tidak tepat pada sasaran. Banyak factor yang menyebabkan hal tersebut terjadi, salahasatunya adalah proses pemberi beasiswa yang masih belum menggunakan metode yang tepat untuk digunakan dalam proses menentukan siapa saja yang berhak menerima beasiswa. Hal ini yang mendasari perlunya sebuah perancangan suatu system informasi berbentuk sebuah aplikasi yang dapat digunakan dalam proses menentukan penerimaan beasiswa untuk para siswa/i dengan menggunakan metode metode Analytical Hierarchy Process (AHP), metode ini dapat membantu melakukan perhitungan untuk menentukan prioritas dengan beberapa kriteria yang dibandingkan serta dilakukan analisa perbandingan secara berpasangan dari masing - masing kriteria yang sudah ditentukan. 


\section{DASAR TEORI}

\section{a. Pengertian Sistem Pendukung Keputusan}

Keputusan merupakan hasil dari suatu proses untuk memilih pilihan yang terbaik dari beberapa alternatif - alternative yang ada. Dalam proses pengambilan keputusan, diperlukan beberapa kriteria yang akan dijadikan perbandingan dan menyusn pembobotan sehingga mendapatkan pilihan yang paling baik. Kegiatan yang diperlukan adalah mengumpulkan data dan informasi yang diperlukan serta menetukan metode pengambilan keputusan yang akan digunakan sebagai dasar untuk mengambil keputusan.

Menurut Maryam Alavi dan H.Albert Napier, Sistem Penunjang Keputusan adalah suatu kumpulan prosedur pemprosesan data dan informasi yang ber orientasi pada penggunaan model untuk menghasilkan berbagai jawaban yang dapat membantu manajemen dalam pengambilan keputusan. (Siadari, 2016)

Sistem Pendukung Keputusan (SPK) atau Decision Support System (DSS) merupakan sebuah sistem yang mampu memberikan kemampuan untuk pemecahan permasalahan maupun kemampuan mengkomunikasikan untuk masalah dengan kondisi semi terstruktur maupun yang tidak terstruktur. Sistem yang digunakan dalam membantu proses pengambilan keputusan dalam situasi semi terstruktur maupun tidak terstruktur, dimana tidak seorang pun yang tahu dengan pasti bagaimana dengan keputusan yang harus dibuat. (Riadi, 2013)

Konsep Dasar Sistem Pendukung Keputusan, pengambilan keputusan meliputi beberapa tahap dan melalui beberapa proses (Lucas,1992). Menurut Simon (1960), dalam proses pengambilan keputusan memiliki 4 (empat) tahapan yang saling berhubungan serta berurutan diantaranya adalah Intelligence, Design, Solusi, Implementation. Pada pemodelan yang digunakan untuk membangun sistem pendukung keputusan, diantaranya sebagai berikut:

1. Studi Kelayakan (Intellegence)

Tahap ini sasaran ditentukan dan dilakukan pencarian prosedur dan pengumpulan data.

2. Perancangan (Design)

Pada tahap ini akan diformulasikan model yang akan digunakan dan kriteria-kriteriayang ditentukan

3. Pemilihan (Choice)

Setelah tahap design ditentukan berbagai alternatif model beserta variabel-variabel.

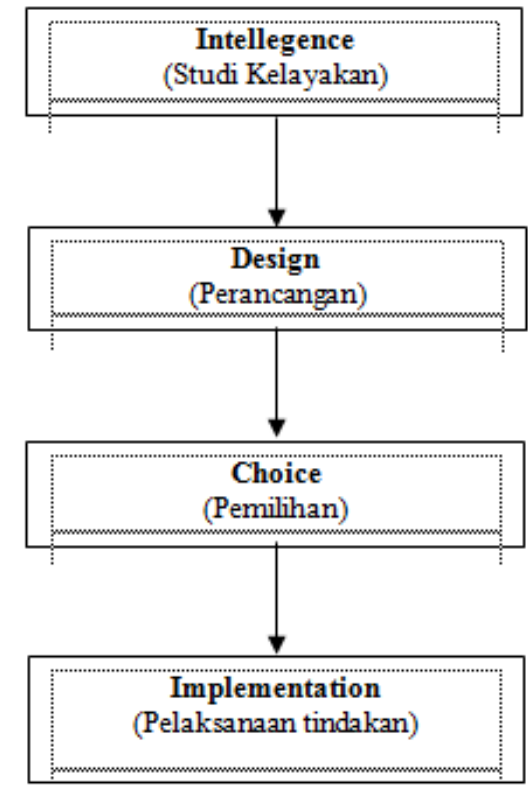

Gambar 1. fase pengambilan keputusan

\section{b. Pengertian Beasiswa}

Bantuan yang diberikan untuk membantu para siswa atau mahasiswa yang masih sekolah atau kuliah supaya mereka bisa menyelesaikan tugasnya dalam mencari wawasan dan ilmu pengetahuan sampai selesai sering disebut dengan beasiswa Beasiswa dalam bentuk bantuan dapat berupa dana sebagai penunjang biaya yang harus dikeluarkan oleh pelajar atau mahasiswa selama menempuh masa pendidikan di tempat belajar. "pengertian Beasiswa merupakan pemberian bantuan dalam bentuk keringanan keuangan yang diberikan kepada seseorang dengan tujuan agar dapat digunakan untuk keberlangsungan proses pendidikan yang akan atau sedang ditempuh. Beasiswa dapat berasal dari bantuan yang dibelikan oleh lembaga pemerintah, perusahaan ataupun yayasan". (Rainer, 2017)

\section{METODE PENELITIAN}

Prores penelitian menggunakan beberapa metode penelitian untuk dapat mendapatkan data data yang digunakan untuk mengoleh maupun mendukung penelitian. Adapun metode yang digunakan disesuaikan dengan kebutuhan dan kesesuaian penelitian yang akan dilakukan. Dalam penelitian ini dikumpulkan data yang dikategorikan dengan beberapa jenis data sebagai berikut :

\subsection{Data Primer}

Data primer ialah data yang menjadi sumber dari penelitian, data ini diperoleh dengan cara wawancara langsung terhadap sumber utamanya melalui jajak pendapat dari individu ataupun kelompok ataupun hasil observasi dari survey kejadian maupun hasil pengujian. 


\subsection{Data Sekunder}

Data sekunder kebalikan dari data primer yaitu sumber data yang di dapatkan melalui proses pengumpulan data yang tak langsung, misalhnya diidapatkan dari pustaka, media, arsip, panduan baik yang terokumentasi dalam bentuk buku, jurnal maupun buti-bukti yang dipublish maupun yang tidak di publlikasikan. (Suntama, 2016)

\subsection{Metode Pengumpulan Data}

Pada proses pengumpulan data digunakan beberapa metode sebagai berikut:

a. Wawancara

Ada dua metode wawancara yaitu wawancara terstruktur dan tidak terstruktur.

b. Observasi

Observasi partisipatif, pada proses pengumpuln data dengan observasi ini, penelitian melihat secara kegiatam sehari hari yag dilakukan orang. Observasi tak berstruktur atau non participant ialah observasi peleneliti tidak secara langsung ikut dalam kegiatan ataupun proses yang akan diamati. (Karnain, 2016)

\subsection{Metode Pengembangan Sistem}

Analytical Hierarchy Process (AHP) adalah sistem pembuat keputusan dengan menggunakan model matematis. Analytical Hierarchy Process (AHP) membantu dalam menentukan prioritas dari beberapa kriteria dengan melakukan analisa perbandingan berpasangan dari masing-masing kriteria. Pada metode AHP ini terdapat empat prinsip penting yang harus dipahami yaitu dekomposisi, perbandingan berpasangan, sistesis prioritas dan konsistensi logis.(Diana, 2018)

Menurut Kadarsyah dan Ali (1998) pada Jurnal siliwangi (Munthafa. A. E, Mubarok. H., 2017), Metode AHP: memiliki langkah-langkah sebagai berikut :

a. Mendefinisikan Permaslahan dan menentukan solusi yang diinginkan.

b. Membuat struktur hierarki dengan diawalai tujuan utama.

Berikut gambar struktur hierarki yang diawali dengan tujuan:

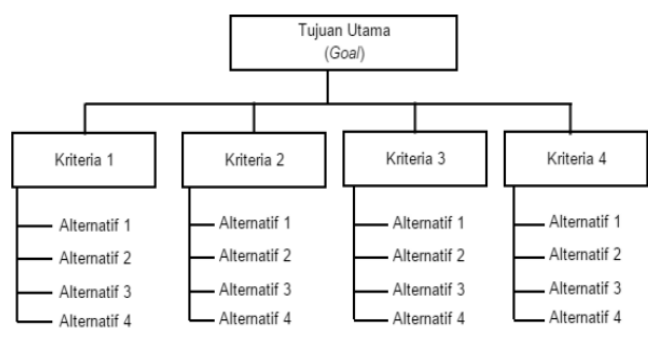

\section{Gambar 2. Stuktur hirarki}

1) Membuat matrik perbandingan berpasangan yang menggambarkan kontribusi relative/ pengaruh setiap elemen terhadap tujuan atau kriteria yang setingkat diatasnya.
Tabel 1. Matriks Perbandingan

\begin{tabular}{lllll}
\hline & $\begin{array}{l}\text { Kriteria- } \\
\mathbf{1}\end{array}$ & $\begin{array}{l}\text { Kriteria } \\
\mathbf{- 2}\end{array}$ & $\begin{array}{l}\text { Kriteria } \\
\mathbf{- 3}\end{array}$ & $\begin{array}{l}\text { Kriteria } \\
\mathbf{- n}\end{array}$ \\
\hline $\begin{array}{l}\text { Kriteria- } \\
\mathbf{1}\end{array}$ & K11 & K12 & K13 & K1n \\
\hline $\begin{array}{l}\text { Kriteria- } \\
\mathbf{2}\end{array}$ & K21 & K22 & K23 & K2n \\
\hline $\begin{array}{l}\text { Kriteria- } \\
\mathbf{3}\end{array}$ & K31 & K32 & K33 & K3n \\
\hline $\begin{array}{l}\text { Kriteria- } \\
\mathbf{n}\end{array}$ & Kn1 & Kn2 & Kn3 & Knn \\
\hline
\end{tabular}

2) Mendefinisikan perbandingan berpasangan dengan tabel sehingga diperoleh jumlah penilai seluruhnya sebanyak $\mathrm{n} \times[(\mathrm{n}-1) / 2]$ buah, dengan $n$ adalah banyaknya elemen yang dibandingkan.

Tabel. 2. Skala Penilaian Perbandingan

\begin{tabular}{cl}
\hline $\begin{array}{c}\text { Itensitas } \\
\text { Kepentingan }\end{array}$ & \multicolumn{1}{c}{ Keterangan } \\
\hline $\mathbf{1}$ & Kedua elemen sama penting \\
\hline $\mathbf{3}$ & $\begin{array}{l}\text { Elemen yang satu sedikit lebih } \\
\text { penting dari elemen lainnya }\end{array}$ \\
\hline $\mathbf{5}$ & $\begin{array}{l}\text { Elemen yang satu lebih } \\
\text { penting dari elemen lainnya }\end{array}$ \\
\hline $\mathbf{7}$ & $\begin{array}{l}\text { Elemen yang satu sangat } \\
\text { penting dari elemen lainnya }\end{array}$ \\
\hline $\mathbf{9}$ & $\begin{array}{l}\text { Elemen yang satu mutlak } \\
\text { sangat penting dari elemen } \\
\text { lainnya }\end{array}$ \\
\hline $\mathbf{2 , 4 , 6 , 8}$ & $\begin{array}{l}\text { Nilai-nilai antaradua nilai } \\
\text { pertimabangan } \\
\text { berdekatan }\end{array}$ \\
\hline Kebalikan & $\begin{array}{l}\text { Jika aktivitas i mendapat satu } \\
\text { angka dibandingkan dengan } \\
\text { aktivitas j, maka j memiliki } \\
\text { nilai kebalikan dibandingkan i }\end{array}$ \\
\hline
\end{tabular}

3) Menghitung nilai eigen serta menguji konsistensi-nya. Jika tidak konsisten maka dapat dilakukan pengambilan data ulang.

4) Ulangi langkah 3, 4, dan 5 untuk seluruh tingkat hierarki.

5) Hitung vektor eigen dari setiap matriks perbandingan berpasangan yang merupakan bobot dari setiap elemen guna menentukan prioritas elemen-elemen pada tingkat hierarki terendah sampai mencapai tujuan.

Untuk mendapatkan nilai rata-rata maka diilakukan proses penghitungan melalui metode penjumlahan nilai dari setiap kolom yang bersangkutan agar memperoleh normalisasi matriks, dan penjumlahan dari nilai-nilai dari setiap baris. Dilanjutkan proses dengan membagi semua jumlah elemen. Jikalau A ialah matriks dari perbandingan bepasangan, maka vektor bobot yang berbentuk: 
$($ A $)(w T)=(n)(w T)$

dapat didekati dengan cara:

a) Menormalkan setiap kolom j dalam matriks A, sedemikian hingga:

$\sum a(i, j) i=1$ sebut sebagai A'.

b) Hitung nilai rata-rata pada setiap baris i dalam

$$
\mathrm{w}_{\mathrm{i}}=\frac{1}{n} \sum_{i} a(i, j)
$$

dengan $\mathrm{w}_{\mathrm{i}}$ ialah bobot tujuan ke-i dari vektor bobot.

6) Memeriksa konsistensi hirarki. Misalkan A merupakan matriks dari perbandingan berpasangan dan $\mathrm{w}$ ialah vektor bobot, maka konsistensi dari vektor bobot dapat diuji sebagai berikut:

a) Hitung: $(\mathrm{A})\left(\mathrm{w}^{\mathrm{T}}\right)$

$$
\mathrm{t}=\frac{1}{n} \sum_{i=1}^{n}\left(\frac{\text { elemen ke- } i \text { pada }(A)\left(w^{T}\right)}{\text { elemen ke-i pada } w^{T}}\right)
$$

Rumus 1. Konsistensi dari Vektor Bobot

b) Hitung indeks konsistensi:

$$
\mathrm{CI}=\frac{t-n}{n-1}
$$

Rumus 2. Konsistensi Indeks

c) Indeks random $\mathrm{RI}_{\mathrm{n}}$ ialah nilai rata-rata $\mathrm{CI}$ yang dipilih secara acak pada A dan diberikan sebagai:

\begin{tabular}{c|ccccccc}
$\mathrm{n}$ & 2 & 3 & 4 & 5 & 6 & 7 & $\ldots$ \\
\hline $\mathrm{RI}_{\mathrm{n}}$ & 0 & 0,58 & 0,90 & 1,12 & 1,24 & 1,32 & $\ldots$
\end{tabular}

d) Hitung rasio konsistensi :

$$
C R=\frac{C I}{R I_{n}}
$$

- Jika CI = 0, maka hierarki konsisten

- Jika CR < 0,1, maka hierarki cukup konsisten

- Jika CR > 0,1, maka hierarki sangat tidak konsisten

\section{HASIL DAN PEMBAHASAN}

4.1 Penerapan Ahp

Pada penerapan AHP dimulai dengan rancangan yang disusun dengan dimulai menyusun stuktur hirarki calon penerimaan beasiswa berprestasi dengan mengambil sampel beberapa siswa untuk dilakukan pemeraan untuk perhitungan menggunakan AHP dengan hasil seperti pada bagan berikut :
Struktur Hierarki Calon Penerima Beasiswa Berprestasi

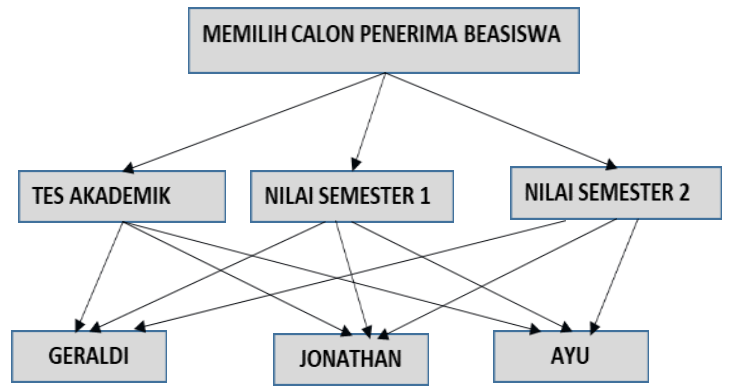

Gambar 3. Stuktur hirarki calon penerima beasiswa

Bedasarkan struktur hirarki yang dilakukan dengan melakukan perbandingan kreteria seperti pada table dibawah ini :

\begin{tabular}{|c|c|c|c|c|c|}
\hline Kriteria & Tes Akademi & ai Semest & is Semester & Mila i igen & Jumlah Rata-tata \\
\hline Tes Aladenik & 1 & 3 & 8,000 & \multicolumn{2}{|c|}{$0,685710,0,6923077 \quad 0,666607,2,046889 \quad 0,681562$} \\
\hline Nilai Senstr1 1 & 0,333 & 1 & 3,000 & $0,228570,2307692$ & $0,250,7034410,236469$ \\
\hline Niáisemstr? & 0,125 & 0,333 & 1 & \multicolumn{2}{|c|}{$0,085710,0,7692310,0,883330,2559710,0,819990$} \\
\hline Jumlah & 1,458 & 4,333 & 12,000 & & 1 \\
\hline
\end{tabular}

Tabel 3. Perbandingan kreteria

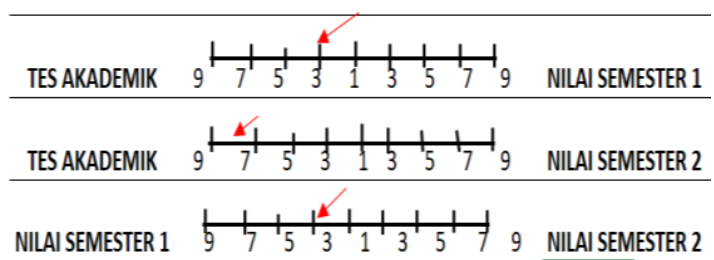

Tabel 4. Matrik perbandingan kriteria

Tabel 5. Perbandingan Alternatif terhadap kriteria

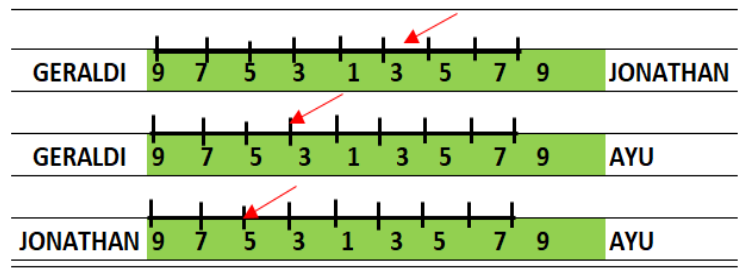

Tabel 6. Matrik perbandingan alternatif terhadap kreteria.

\begin{tabular}{|ccccccccc|}
\hline TES AKADEMIK GERALDI JONATHAN & AYU & \multicolumn{3}{c|}{ NILAI EIGEN } & \multicolumn{3}{c|}{ JUMLAH RATA-RATA } \\
\hline GERALDI & 1 & 0,5 & 3 & 0,3 & 0,29412 & 0,3333 & 0,927 & 0,309150 \\
\hline JONATHAN & 2 & 1 & 5 & 0,6 & 0,58824 & 0,5556 & 1,744 & 0,581264 \\
\hline AYU & 0,333 & 0,2 & 1 & 0,1 & 0,11765 & 0,1111 & 0,329 & 0,109586 \\
\hline JUMLAH & 3,333 & 1,7 & 9 & & & & & 1 \\
\hline
\end{tabular}


Tabel 7. Perbandingan alternatif terhadap kretria semester 1

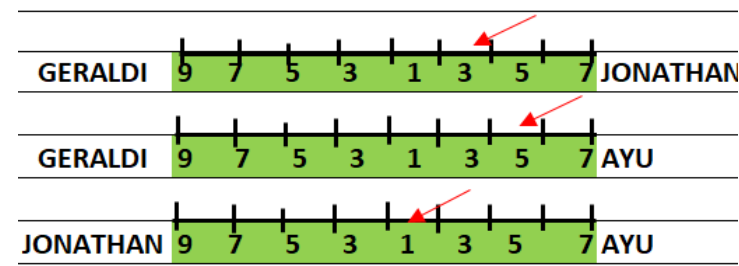

Tabel 8 Matriks Perbandingan alternatif terhadap kretria semester 1

\begin{tabular}{cccccc|cccc}
\hline NILAI SEMESTER 1 & GERALDI IONATHAN AYU & \multicolumn{2}{c}{ NILAI EIGEN } & \multicolumn{3}{c}{ JUMLAH RATA-RATA } \\
\hline GERALDI & 1 & 0,25 & 0,25 & 0,111 & 0,077 & 0,143 & 0,331 & 0,110297 \\
\hline JONATHAN & 4 & 1 & 0,5 & 0,444 & 0,308 & 0,286 & 1,038 & 0,345950 \\
\hline AYU & 4 & 2 & 1 & 0,444 & 0,615 & 0,571 & 1,631 & 0,543753 \\
\hline JUMLAH & 9,000 & 3,25 & 1,75 & & & & & 1 \\
\hline
\end{tabular}

Tabel 9 Perbandingan alternatif terhadap kreteia semester 2

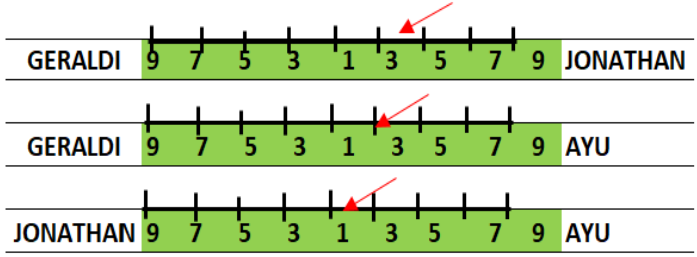

Tabel 10 Matrik Perbandingan alternatif terhadap kreteia semester 2

\begin{tabular}{ccccccccc|}
\hline NILAISEMESTER 2 & GERALDI JONATHAN AYU & \multicolumn{2}{c|}{ NILAI EIGEN } & \multicolumn{3}{c|}{ JUMLAH RATA-RATA } \\
\hline GERALDI & 1 & 0,25 & 0,333 & 0,125 & 0,077 & 0,182 & 0,384 & 0,128 \\
\hline JONATHAN & 4 & 1 & 0,500 & 0,500 & 0,308 & 0,273 & 1,080 & 0,360 \\
\hline AYU & 3 & 2 & 1,000 & 0,375 & 0,615 & 0,545 & 1,536 & 0,512 \\
\hline JUMLAH & 8,000 & 3,25 & 1,833 & & & & 1,000 \\
\hline
\end{tabular}

\subsection{Menentukan Perankingan}

Hasil akhir dari penerapan perhitungan AHP yang dilakukan dalam perankingan yang didapatkan dengan hasil perhitungan sebagai berikut:

Berdasarkan perhitungan matriks perbandingan kretiria yang diambil dari rata-rata :

$$
\begin{aligned}
& \text { C1 = lamda max-n/n-1 } \\
& \text { Lamda max }=\left(1,458^{*} 0,681\right)+\left(4,333^{*} 0,236\right)+(12 * 0,081) \\
& =3,002 \\
& \mathrm{n}=3 \\
& \mathrm{C} 1=3,002-3 / 3-1 \\
& =0,001
\end{aligned}
$$

Maka, $\mathrm{CR}=\mathrm{CI} / \mathrm{IR}$

$=0,001 / 0,58$

$=0,002$
Hasil dari CR kurang dari 0,1 berarti konsistensi.

Berdasarkan perhitungan matriks perbandingan kretiria yang diambil dari rata-rata :

C1 = lamda max-n/n-1

$$
\begin{aligned}
& \text { Lamda max }= \\
& (3,333 * 0,309)+(1,7 * 0,581)+(9 * 0,109) \\
& =3,004 \\
& \mathrm{n}=3 \\
& \mathrm{C} 1=3,004-3 / 3-1 \\
& =0,002 \\
& \text { Maka, CR }=\mathrm{CI} / \mathrm{IR} \\
& =0,002 / 0,58 \\
& =0,004
\end{aligned}
$$

Hasil dari CR kurang dari 0,1 berarti konsistensi

Berdasarkan perhitungan matriks perbandingan alternatif kretiria yang diambil dari rata-rata :

C1= lamda $\max -\mathbf{n} / \mathbf{n}-1$

Lamda $\max =$

$(9,000 * 0,110)+(3,25 * 0,345)+\left(1,75^{*} 0,543\right)$

$$
\begin{aligned}
& =3,068 \\
& \mathrm{n}=3 \\
& \mathrm{C} 1=3,068-3 / 3-1 \\
& =0,034 \\
& \text { Maka, CR = CI/ IR } \\
& =0,034 / 0,58 \\
& =0,059
\end{aligned}
$$

Hasil dari CR kurang dari 0,1 berarti konsistensi

Berdasarkan perhitungan matriks perbandingan alternatif kretiria yang diambil dari rata-rata :

\section{C1= lamda max-n/n-1}

Lamda $\max =$

$$
\begin{aligned}
& (8,000 * 0,128)+(3,25 * 0,360)+(1,833 * 0,512) \\
& =3,132 \\
& \mathrm{n}=3 \\
& \mathrm{C} 1=3,132-3 / 3-1 \\
& =0,066 \\
& \text { Maka, } \mathrm{CR}=\mathrm{CI} / \mathrm{IR} \\
& =0,066 / 0,58 \\
& =0,001
\end{aligned}
$$

Hasil dari CR kurang dari 0,1 berarti konsistensi

Berdasarkan hasil perhitungan diatas dihasilkan perankingan sebagai berikut : 
Geraldi $=(0,681 * 0,309)+(0,236 * 0,110)+(0.081 *$ 0,128 )

$$
=0,2473
$$

Jonathan $=(0,681 * 0,581)+(0,236 * 0,345)+(0,081 *$ 0,360 )

$$
=0,5075
$$

$\underset{0,512)}{\text { Ayu }}=(0,681 * 0,169)+(0,236 * 0,543)+(0,081 *$ $=0,245$

Tabel 11 Perangkingan

\begin{tabular}{cc}
\hline GERALDI & $\mathbf{0 , 2 4 7 3}$ \\
\hline JONATHAN & 0,5075 \\
\hline AYU & 0,24523
\end{tabular}

Dari tabel 11. diatas disimpulkan bahwa penerima beasiswa berprestasi ini adalah Jonathan dengan hasil perhitungan 0,5075 .

\subsection{Pengembangan Kedalam Aplikasi Web}

Pada penelitian yang dilakukan ini di hasilkan sebuah system informasi berupa aplikasi berbasis web yang memiliki beberapa fitur yang langsung dapat menetukan siswa yang memiliki kesempatan mendapatkan beasiswa berprestrasi dengan kreteria dan pembobotan yang telah ditentukan oleh pihak sekolah. Aplikasi web ini dapat dioperasikan oleh 2 operator yaitu admin dan siswa. Admin memiliki fitur yang lengkap dari tambah, simpan, hapus, update menu yang ada di fitur-fitur yang digunakan untuk penentuan perankingan siswa beprestasi. Sedangkan siswa dapat mengajukan dengan menginputka beberapa persyaratan yang diminta disertai buktibukti yang dibutuhkan.

\section{KESIMPULAN}

Berdasarkan hasil analis masalah dan pembahasan, hasil yang dimulai dari proses pengumpulan data, analisa dan dilakukan perancangan dari penentuan kriteria, proses pembobotan nilai dari kriteria, proses perhitungan, membangun aplikasi untuk proses yang langsung dapat dilihat dan mengeluarkan informasi keputuan secara cepat sehingga disimpulkan dari penelitian ini adalah dengan adanya sebuah aplikasi yang dibangun dengan menggunakan perhitungan metode AHP (Analityc Hierarchy Process (AHP) pada SMA NEGERI 1 NATAR Lampung Selatan sehingga Sistem Pengambilan Keputusan Penerimaan Beasiswa menggunakan mempermudah dalam mengambil keputusan untuk menentukan penerima beasiswa.

Agar keamanan data terjamin dan tidak sembarang diakses maka disarankan untuk memberikan sistemkeamanan dengan membuat username dan password pada database dan agar dapat memaksimalkan kerja sistem disarankan agar pengguna menggunakan perangkat lunak yang peneliti sarankan.

\section{DAFTAR PUSTAKA}

[1] Gerald. (2017, Oktober). Pengertian Sistem Pengambil Kebutusa(SPK) Beserta Contoh nya. Retrieved Januari Jumat, 2019, from https://

www.codepolitan.com/2017/10/16/pengertia n-sistem-pengambil-keputusan-spk-besertacontohnya/

[2] Siadari, C. (2016, Juni). Kumpulan Pengertian. Retrieved Februari Kamis, 2019, from Info dan Pengertian Website: http://www.infodanpengertian.com

[3] Lucas JR, Henry C., (1987), "Analisis, Desain, Dan Implementasi Sistem Informasi". Penerbit Erlangga, Edisi ke-tiga, Jakarta,

[4] Simon, A. Herbert, (2004),. "Administrative Behavior, Perilaku Administrasi : Suatu Studi tentang Proses Pengambilan Keputusan dalam Organisasi Administrasi". Edisi Ke-tiga, Cetakan Ke-empat, Alih Bahasa ST. Dianjung, Bumi Aksara, Jakarta.

[5] Riadi, M. (2013, September 18). sistempendukung-keputusan. Retrieved Februari Rabu, 2019, from Kajian Pustaka.com: https://www.kajianpustaka.com/2013/09/sis tem-pendukung-keputusan- spk.html

[6] Rainer, D. (2017, Oktober). Retrieved Februari Kamis, 2019, from https://www.studinews.co.id

[7] Karnain, Z. (2016). Makalah Pengumpulan Data. Retrieved Februari, 2019 http://www.academia.edu/8204425/Makalah _Pengumpulan_Data

[8] Diana., (2018), Metode \& Aplikasi Sistem Pendukung Keputusan, Palembang: Deepublish.

[9] Munthafa. A. E, Mubarok. H, (2017), Penerapan Metode Analytical Hierarchy Process Dalam Sistem Pendukung Keputusan Penentuan Mahasiswa Berprestasi, Jurnal Siliwangi, Pg. 192-201

[10] Suntama. (2016, Oktober 19). Kanal Informasi. Retrieved Juni 2019, from https://www.kanalinfo.web.id/pengertiandata-primer-dan-data-sekunder 